\title{
En torno a los criterios y consideraciones sobre la puntuación en ediciones críticas de textos literarios medievales*
}

\author{
Miguel Las Heras Calvo \\ Universidad de La Rioja \\ miguel.las-heras@unirioja.es
}

\section{INTRODUCCIÓN}

Como es bien sabido, el principal objetivo de las ediciones críticas consiste en fijar el texto de una obra, atendiendo a toda su tradición escrita. La presentación del texto definitivo implica el análisis y la interpretación de variantes, tipos de errores o cuestiones de tipo lingüístico, entre otros, que persiguen una presentación formal que elimine los elementos irrelevantes y reconstruya, en la medida de lo posible, el texto original del autor. En este proceso, más concretamente en la dispositio textus, los editores se ven obligados a tomar decisiones sobre los criterios de presentación gráfica: elección de una u otra grafía, unión o separación de palabras, acentuación y puntuación son aspectos que se tratan en esta fase de la edición.

Precisamente, uno de los aspectos más complicados a los que se enfrenta un editor es la puntuación. Este, partiendo de los signos del manuscrito o manuscritos (en el caso de disponer de ellos), tiene que adoptar unas decisiones para conseguir que el texto sea inteligible y ajustado al original. Ambas puntuaciones -la del testimonio y la editada- son fundamentales «para el conocimiento de la lengua del manuscrito» (Fernández López 2014: 23), ya que un estudio previo de los posibles hábitos interpuntivos del manuscrito ayudará a su interpretación y, consecuentemente, a su posterior edición (Bédmar Sancristóbal 2006: 131). Sin embargo, son numerosas las complicaciones ante las que se encuentra el editor en la toma de decisiones sobre este aspecto: manuscritos sin puntuación, posibles dudas en la priorización de criterios rítmicos y/o sintácticos, aplicación de nuestro sistema de signos vigente a estructuras sintácticas diferentes a la actuales, respeto (o no) de los signos insertos

* Este trabajo se enmarca en las actividades del proyecto DHuMAR II: From Middle To Golden Age: Translation \& Tradition (Ref.: PY20_00469, Proyecto financiado por la Consejería de Transformación Económica, Industria, Conocimiento y Universidades de la Junta de Andalucía y por FEDER Una manera de hacer Europa). 
en los manuscritos, variaciones de los signos en la transmisión textual o diversas interpretaciones textuales en función de la inserción (o no) de un signo $u$ otro $^{1}$. A esto hay que sumarle el desconocimiento que se tiene en el ámbito hispánico actualmente de las funciones y de los usos de las marcas con que los amanuenses entreveraban sus textos ${ }^{2}$; signos que, en muchas ocasiones, han sido juzgados como «arbitrarios» y usados «sin criterios fijos».

Dichas complicaciones se vienen anunciando, al menos, desde finales de los años 50 por parte de editores que reclamaban la necesidad fundamental de comprender el empleo de estos signos para así poder actuar de manera solvente en la edición de los textos medievales ${ }^{3}$. Dada la complejidad de la cuestión y la carencia de recursos a los que acudir en caso de ayuda, ha sido una tendencia muy habitual optar por la modernización en el uso de estos signos, ya que facilita la lectura y el entendimiento del texto (Roudil 1978: 271). Sin embargo, cabría preguntarse, de acuerdo con los principios de la crítica textual, si es esta la opción idónea.

El propósito de este trabajo es, por tanto, revisar las pautas que algunas de las personalidades más relevantes del ámbito de la ecdótica han aconsejado en sus manuales (o trabajos) de crítica textual y, asimismo, observar cuáles han sido las maneras más habituales de proceder a partir de la consulta de 85 ediciones críticas de textos literarios medievales. En otras palabras, se pretende cotejar si hay correspondencia entre las recomendaciones (y criterios) de los primeros y las consideraciones que los editores hacen sobre esta cuestión en su apartado correspondiente.

\footnotetext{
${ }^{1}$ Véase al respecto, por ejemplo, Orduna (2005: 67 y 68), donde extrae dos ejemplos de la Crónica del rey don Pedro y del rey don Enrique para explicar las posibles lecturas en función de la decisión tomada respecto a estos signos.

${ }^{2}$ En el Coloquio en París sobre frases, textos y puntuación en los manuscritos medievales españoles (París, 1981), se subrayó la importancia de estudiar y entender estos signos, que se hallan directamente vinculados a la crítica textual (López Estrada 1982). Aun así, no son muchas las investigaciones hasta el momento que se han dedicado a interpretar los usos de estos signos. Véase al respecto el apartado bibliográfico $\S$ «6 Théorie et pratiques de la ponctuation dans les textes hispaniques», de Llamas Pombo (2008: 169 y ss.). Además, se han publicado otros estudios más recientes a propósito de textos literarios, como los de Sánchez-Prieto (2018) o Las Heras Calvo (2020), ambos referidos a los signos interpuntivos de la General estoria de Alfonso X.

${ }^{3}$ La primera referencia encontrada es de la hispanista Margherita Morreale (1958) en su edición de Los doze trabajos de Hércules de Enrique de Villena. En ella, ya aludía a los problemas que planteaba la puntuación de este texto en concreto: «queda abierto el problema de la puntuación de la prosa medieval». De esta misma manera, Vitalino Valcárcel (1982: 81-82), en su edición de la Vita Dominici Silensis, manifestaba los contratiempos que había tenido en su edición: «La puntuación, que me ofreció problemas y dudas en múltiples ocasiones, porque ella exterioriza de algún modo la comprensión del texto que hay delante, es enteramente de mi responsabilidad, pues, una vez más, no tenía dónde acudir en busca de ayuda [...]» (la cursiva es nuestra).
} 


\section{ORIENTACIONES DE los MANUALES TEÓRICOS DE CRÍtica TEXTUAL A PROPÓSITO DE LA PUNTUACIÓN}

Uno de los primeros trabajos que se preocuparon por guiar al editor en el proceso de edición de los signos de puntuación fue el realizado por Morreale (1980), a propósito de los problemas que encontró en la edición de estos signos, ejemplificados en la Biblia romanceada E6. Los diferentes criterios empleados en los textos medievales respecto a los signos, la (muchas veces) errática puntuación de los manuscritos o la aplicación de los signos actuales -con valores ya muy definidos- a estructuras diferentes a las actuales son aspectos que, como afirma la autora, dificultan enormemente dicha tarea. Aun así, Morreale (1980: 151) es partidaria, en todo caso, de la observación de los signos de puntuación del manuscrito como primer requisito fundamental, independientemente de que estos se tomen en consideración o no: «ha de sopesarse la puntuación del manuscrito, o manuscritos, pero sin poderla obtemperar en muchos casos $[\ldots] \gg$. De este modo, partiendo de la estructura sintáctica de este romanceamiento (predominio de estructuras paratácticas, abundancia de conjunciones y otros elementos de tipo discursivo), fija los criterios que la guían en la toma de decisiones en la edición de los signos interpuntivos (signos de interrogación, admiración, dos puntos, el punto, el punto y coma, y la coma) con una minuciosidad admirable ${ }^{4}$. Con todo, se adelantó a las posibles críticas que otros investigadores podrían verter hacia su propuesta eminentemente sintáctica:

Se nos objetará que al apartarnos del ritmo en el interior de la oración ${ }^{5}$, y al tomar criterios semánticos de claridad como regla de interpunción, nos apartamos de la naturaleza de los signos, melódicos en su origen, y

${ }^{4}$ Rescatamos algunas pautas concretas basadas, como anotamos, en criterios sintácticosemánticos y textuales, que constituyen buena prueba de la meticulosidad: «Nos valdremos del (.) como del elemento conectivo entre oraciones completas, aunque breves, cuando no estén ligadas por nexos explícitos» (Morreale 1980: 157); «Empleamos (:) no solo para introducir un discurso directo tras un verbum dicendi $[. .$.$] , sino también en los pasajes en que el hagiógrafo$ interviene sin más con una exhortación» (Morreale 1980: 156); «En periodos de tres o más miembros, el (;) en presencia de la conjunción coordinativa tiene también la función de marcar el agrupamiento de dos de ellos, separados por (,) frente a otro tercero (Morreale 1980: 158)»; «Emplearemos (,) ante conjunción cuando la proposición que sigue es consecutiva o epexegética (Morreale 1980: 161)».

${ }^{5}$ En relación con el uso de la (,), anotaba «si ha de ser la claridad y no el ritmo lo que determine la puntuación, no nos guiaremos por la pausa ante verbo con pronombre átono enclítico o ante futuro con pronombre átono». No obstante, respecto a la puntuación referida a las proposiciones coordinadas apuntaba lo siguiente: «esperamos haber desatacado la mayor fidelidad de E6 al ritmo del original (el romanceamiento a veces va más allá de la Vulgata cuando suprime los nexos introducidos en la traducción latina)» (Morreale 1980: 174). Así, en otros apartados estima también la necesidad de acomodar los signos al ritmo: «No nos podremos sustraer, sin embargo, a las exigencias del ritmo cuando la anticadencia del primer miembro [referido a las apódosis de las subordinadas condicionales o a estructuras comparativas] se alarga» (Morreale 1980: 168). 
creamos normas empíricas que no siempre son necesarias [...]. A esto contestamos que la decisión no puede dejarse a cada caso particular [...], y a aquello, que el uso de la (,) para indicar el ritmo, si es dudoso en una edición moderna [...], lo es aún más en un texto del que no podemos conocer la realización oral, y cuyas características morfológicas nos inducirían a sobrecargar el texto [...]. (Morreale 1980: 174 y 175)

Sin embargo, como apunta Sánchez-Prieto (1998: 182), aunque muchas de las guías que se sugieren en este trabajo podrían aplicarse a otros textos, la biblia romanceada E6 cuenta con una serie de características distintivas en su estructura sintáctica oracional que impide aplicar de forma sistemática todos y cada uno de los preceptos que se enumeran a otras obras.

Alberto Blecua, por su parte, estima oportuno puntuar el texto atendiendo a la velocidad y el ritmo del texto. En su Manual de crítica textual afirma, respecto a la edición de textos medievales, que «los editores tienden [...] a puntuar con el actual sistema de signos y normas, acomodándolos al peculiar ritmo de la frase medieval» (Blecua 1990: 140). Es cierto que este consejo no se presenta como una prescripción, sino más bien como un hábito entre los editores ${ }^{6}$, ya que debido a los problemas que surgen en la dispositio textus (grafías, división de palabras, acentuación o puntuación), «un crítico puede actuar de modo muy distinto según el tipo de texto a que se enfrente» (Blecua 1990: 138)7. Efectivamente, la tipología textual condicionará determinantemente las soluciones adoptadas por el especialista, quien en muchas ocasiones no encuentra en el sistema actual de signos de puntuación una ayuda, sino más bien una limitación, pues no permite señalar matices que se hallan en algunos manuscritos. El mismo Blecua (2010: CI), en su edición del Libro de buen amor, afirmaba lo siguiente:

La puntuación de la obra es muy compleja por la estructura de la copla, que tiende a la sentencia, por lo que los puntos (:) deberían encerrarse en otros dos, contra la RAE, pero no contra la entonación del libro. He seguido a la RAE como obligación moral, pero con sus normas hay que hacer equilibrios de expertos malabaristas tonemáticos.

La adopción de las normas de puntuación de la ortografía académica - que se ve obligado a seguir- resulta inadecuada, porque existe

${ }^{6}$ Se plantea de la misma manera para los textos de los siglos XVI y xVII: «Habitualmente los editores suelen seguir el uso moderno, auxiliándose para casos ambiguos de la puntuación antigua» (Blecua 1990: 143).

${ }^{7}$ En su obra La edición de textos, Pérez Priego alude asimismo a la manera más habitual de proceder: «También para la puntuación lo corriente es adoptar el sistema moderno, aunque tanto la escritura manuscrita de la Edad Media como luego la imprenta difundieron algunos usos particulares, que no parece llegaran a alcanzar general aceptación» (Pérez Priego 2011: 85). 
una disonancia clara entre los criterios con que se utilizan los signos en su manuscrito y los de la Academia. En la actualidad, según la RAE y ASALE (2010: 288), «la puntuación se basa principalmente en la estructura sintáctico-semántica de los enunciados y los textos». Esta decisión académica de tomar como criterios estos dos planos de la lengua deja al margen, en un principio, el prosódico, valor posiblemente presente en los signos de muchos de los textos editados ${ }^{8}$.

Entre las obras que más espacio dedican a la fijación de criterios para la edición de los signos que nos competen, se halla la elaborada por Sánchez-Prieto (1998), Cómo editar los textos medievales. Criterios para su presentación gráfica. El autor es plenamente consciente de la dificultad que entraña establecer unas orientaciones para la edición de los signos interpuntivos, pues resulta de gran complejidad captar la totalidad de los matices de la sintaxis antigua. Dicha dificultad se ve incrementada, si cabe, en las ediciones de los textos poéticos por la tensión que puede darse entre el ritmo y la sintaxis: «El editor se moverá en la cuerda floja entre la delimitación de la sintaxis y el exigible relieve del ritmo» (Sánchez-Prieto 1998: 182). En estos casos, Sánchez-Prieto se decanta por una solución sintáctico-lógica que facilite la comprensión de los textos. De todos modos, la observación del manuscrito y de sus signos de puntuación debe ser el primer paso que el editor debe afrontar para su edición, independientemente de que dichos signos se sigan o no. De esta manera, tras reseñar brevemente los valores de los signos más empleados ${ }^{9}$, da algunas indicaciones que se deberían seguir para su edición, atendiendo, como decimos, a estructuras sintácticas e intentando respetar los rasgos propios de la sintaxis medieval: (cor)relación de elementos, complementos circunstancial y régimen, uso expletivo de $e$,

\footnotetext{
${ }^{8}$ Exactamente lo mismo ocurre en francés con el desajuste entre criterios en el uso de la puntuación medieval y actual, que supone una traba en la edición: «la ponctuation du français standard (c'est- à-dire non littéraire), de conception analytique, tend moins vers un éclairage prosodique (rythme, intonation, pause...) que vers un éclairage formel de la phrase et du texte, fondé sur des critères syntaxiques, sémantiques, communicationnels et énonciatifs» (Bragantini-Maillard 2013: 325).

${ }^{9}$ Distingue las pausas tradicionales: pausas mayores, como el calderón (ף), a las que el editor debe darles «entidad textual, y por tanto deberían reflejarse en el aparato crítico [...]» (Sánchez-Prieto 1998: 183); y menores (o internas), de las que se afirman que «por su menor estabilidad y por su pobreza, es menos orientativa para el editor» (íd.). Respecto a este último tipo de puntuación, entendemos que el comentario resulta demasiado amplio -consecuencia del tipo de manual ante el que nos encontramos- $y$, efectivamente, muchos manuscritos ni siquiera disponen de signos de puntuación, como pudieran ser el manuscrito v. 7-17 (BNE), que contiene el Cantar de Mio Cid, o el manuscrito 11309 (BNE), con el Libro del caballero Zifar; sin embargo, creemos que dicha afirmación no se puede extrapolar a un gran número de manuscritos medievales. Algunos ejemplos de códices o textos que sí disponen de dichos signos son, entre otros muchos, los manuscritos 816 (BNE) y 539 Urb. Lat. (BAV), códices regios alfonsíes de la General estoria, el texto de Los diez mandamientos, copiado en el manuscrito 3576 (BNP) o el 9433 (BNM), que contiene Los sermones atribuidos a Pedro Marín (h. 1425). Esta información se podrá complementar con la revisión de $\S 3$.
} 
pronombres expletivos, cláusulas explicativas y especificativas y, por último, los valores de la conjunción $q u e^{10}$.

Por otra parte, en la obra La edición de textos españoles medievales y clásicos (Sánchez-Prieto 2011), se establecen en cuatro puntos las indicaciones básicas para la puntuación de los textos españoles medievales y clásicos.

De nuevo, se prefiere un proceder en el que el editor, utilizando los signos de puntuación actuales y fijándose en la puntuación del documento con que se esté trabajando, refleje la sintaxis - para las obras en prosa- junto con la prosodia - para las versificadas- propias de la época (Sánchez-Prieto 2011: 30):

1. Se emplearán los signos de puntuación vigentes (punto, coma, dos puntos, interrogación, etc., pero no calderón, barra inclinada, etc.).

2. Se puntuará de modo que, mediante el sistema actual, se refleje en la medida de lo posible la sintaxis del documento. En los textos en verso la puntuación ha de tener muy en cuenta la prosodia.

3. Se debe atender a las marcas de puntuación del manuscrito o el impreso por su posible valor indicativo respecto de dependencias o relaciones sintácticas y semánticas.

4. La puntuación ha de representar la propuesta de lectura que hace el editor $[\ldots]$.

Aunque no es el propósito de este trabajo, cabe mencionar que Sánchez-Prieto establece diferencias entre distintos tipos de texto en sus propuestas de edición y, consecuentemente, sobre su puntuación. Así pues, mientras las indicaciones vistas estaban diseñadas principalmente para los textos literarios, para la documentación hispánica se ve necesaria una triple edición: facsimilar, paleográfica y crítica. Esta decisión surge de la diversidad de intereses -no exclusivamente filológicos- relacionados con este tipo de texto: fonético-fonológicos, morfológicos, sintácticos, paleográficos, diplomáticos, históricos, etc. (Sánchez-Prieto 2011: 34). Por tanto, la puntuación de la documentación dependerá del tipo de edición ${ }^{11}$.

${ }^{10}$ Ejemplifica cada estructura a partir de las soluciones que otros editores han dado a sus ediciones de textos medievales y enmienda algunos errores. Los textos que escoge son mayoritariamente prosísticos, por ejemplo, la edición del Lapidario de Rodríguez M. Montalvo, la Crónica general vulgata de Bustos Guadaño, la Primera parte de la General estoria de Solalinde, el Libro de los doce sabios de Walsh o el Victorial de Miranda (Sánchez-Prieto 1998: 184-188).

${ }^{11}$ Por ejemplo, respecto a la edición paleográfica, se respetan en líneas generales los signos utilizados en el manuscrito, incluyendo cuando sea preciso otros signos, como la barra (/), el guion (-) o el calderón (ף). No obstante, se realizan algunas modificaciones relacionadas con la altura en la que se disponen los puntos respecto a la caja de escritura, pues se opta por transcribir el punto alto y el medio en la parte baja del renglón, o se prefiere la opción punto y coma (;) en vez de la más habitual (.') (Sánchez-Prieto 2011: 55 y 56). En cuanto a la puntuación en la edición crítica, dos indicaciones son las que guían la actuación del editor. Ambas están 
Germán Orduna (2005: 65), a propósito de la interpretatio, alude a la necesidad del editor de decidir sobre la prosodia del texto ofrecido, donde los signos de puntuación se revelan como marcas que ayudan en la lectura de textos, en los que la sintaxis, los conectores o las fórmulas del texto escrito estaban pensadas para ser declamadas ante un público. De esta manera, critica las versiones modernizadas, ya que no considera que sea este el propósito de la ecdótica, sino «mantener e integrar un sistema de signos, mediante la interpunción, por el cual se pueda actualizar la prosodia y la imagen fónica que originalmente fue creada para ese texto en vulgar» (Orduna 2005: 66).

Aunque la mayoría de los autores coincidan en, por ejemplo, la observación y estudio de la puntuación manuscrita, observamos, en definitiva, la dificultad con la que los estudiosos se encuentran al pautar dichas indicaciones: la sintaxis, el ritmo y la prosodia medievales deben adaptarse al actual sistema de puntuación. Esta adaptación parece venir condicionada por la tipología a la que se adscriben las obras editadas. De este modo, para las obras en prosa, se tiende a la adopción de criterios sintáctico-semánticos, respetando (en la medida en que se puede) el periodo frástico medieval; mientras que para las obras en verso se contemplan además indicaciones de tipo rítmico-prosódico. No hay que olvidar que estas pautas coinciden en buena medida con las investigaciones sobre los usos y funciones de la puntuación medieval en estos tipos de texto, de modo que dichas indicaciones, creemos, recogen adecuadamente el valor de los signos manuscritos medievales.

\section{ANÁLISIS Y CLASIFICACIÓN DE LOS APARATOS CRÍTICOS DE EDICIONES DE} TEXTOS MEDIEVALES LITERARIOS

No cabe duda de que la observación y estudio de la puntuación del manuscrito debe ser el primer paso que el editor debe afrontar en la edición de estos signos. Sin embargo, en la práctica, Roudil (1978: 270272) ya afirmaba que la mayor parte de los editores no asumían esa primera etapa y catalogó las diferentes formas de proceder en tres grupos básicos ${ }^{12}$ :

a) No se alude a los criterios que se han seguido al editar la puntuación del manuscrito.

b) Los signos de puntuación, así como sus usos y funciones, se modernizan y se utilizan según las normas actuales.

basadas en el análisis y la reproducción, a partir del sistema de signos actual, de la sintaxis y las partes del documento: «- Se ha de reflejar mediante el sistema actual de puntuación la sintaxis del documento, no la moderna. - Hay que prestar atención a las estructuras formularias de los documentos para ofrecer una puntuación coherente y sistemática» (Sánchez-Prieto 2011: 67).

${ }^{12}$ Extrae esta clasificación a partir de la consulta de una veintena de ediciones críticas. 
c) La puntuación del texto crítico se establece siguiendo las normas modernas, pero valorando y sopesando las funciones de las marcas del manuscrito.

Efectivamente, estos tres tipos definen y acotan de manera general perfectamente las posturas adoptadas por los editores. Además, en la práctica el número de soluciones es mucho más amplio, lo cual complica su estudio. Para corroborar esta idea, partiendo de esta tipología, hemos revisado los criterios de edición de más de ochenta obras medievales. Concretamente, se ha consultado un total de 85 ediciones de textos literarios de los siglos XII al $\mathrm{XV}^{13}$. En la siguiente tabla se observan, a la izquierda, las diversas opciones por las que optan los editores de estas obras. Las tres primeras posturas son las apuntadas por Roudil y las siguientes, otras que hemos recogido en el correspondiente apartado de las obras consultadas. A la derecha, el número de ediciones que adopta cada una de las opciones con su correspondiente porcentaje.

\begin{tabular}{|l|c|}
\cline { 2 - 2 } \multicolumn{1}{l|}{} & $\begin{array}{l}\text { Ediciones de textos } \\
\text { literarios }\end{array}$ \\
\hline A) Ninguna alusión & $29,4 \%$ \\
& $25 / 85$ \\
\hline B) Se moderniza la puntuación & $34,1 \%$ \\
& $29 / 85$ \\
\hline C) Se moderniza la puntuación teniendo en cuenta la del & $9,4 \%$ \\
manuscrito & $8 / 85$ \\
\hline D) Se moderniza la puntuación, se alude a los signos & $10,5 \%$ \\
manuscritos y/o se realiza un estudio más o menos detallado & $9 / 85$ \\
\hline E) Se conserva la puntuación del manuscrito & $2,5 \%$ \\
& $2 / 85$ \\
\hline F) Se realiza doble o triple edición & $3,5 \%$ \\
& $3 / 85$ \\
\hline G) Se basa en otras ediciones ya elaboradas & $7 \%$ \\
& $6 / 85$ \\
\hline H) Otras opciones & $3,5 \%$ \\
\end{tabular}

TABla 1. Consideraciones en torno a la edición de la puntuación en 85 ediciones de textos literarios medievales y porcentajes que suponen en nuestro cotejo

\footnotetext{
${ }^{13}$ Nos hemos basado, fundamentalmente, en las obras (que no ediciones) que conforman el recorrido literario trazado por González Ollé en su obra Lengua y literatura españolas medievales (1980). Algunas de las ediciones que se han estudiado pertenecen a las siguientes obras o textos medievales: lírica popular, Cantar de mío Cid, Vida de Santa María Egipcíaca, Libro de Apolonio, Libro de Alexandre, poemas hagiográficos, obras de Gonzalo de Berceo, Poema de Fernán González, Calila e Dimna, Sendebar o Libro de los engaños, la General estoria, Los castigos de Sancho IV, el Poema de Yuçuf, El caballero Cifar, El conde Lucanor, el Libro de buen amor, Poema de Alfonso XI, Proverbios de Salomón, Cancioneros (Palacio, Estúñiga, Baena), Danza de la Muerte, Amadís de Gaula, Corbacho, Siervo libre de Amor, Laberinto de Fortuna, poesía de Jorge Manrique, Cárcel de amor, autos sacramentales o la Celestina.
} 
En líneas generales, los tres tipos anotados por Roudil son los más habituales, ya que entre ellos sus porcentajes suman más de la mitad de las posturas adoptadas al tratar estos signos. Pero además se han detectado otros matices y apreciaciones cuyos editores apuntan en sus obras: se alude y/o se estudia la puntuación del (o de los) manuscrito(s), se sigue la puntuación del manuscrito o se elabora una doble o triple edición, que serviría para abarcar los múltiples intereses de los textos. Comentamos brevemente algunos aspectos que se han hallado en estas ediciones ${ }^{14}$.

\subsection{Ninguna alusión a los criterios de puntuación}

Llama la atención el elevado número de ediciones que no hacen ninguna alusión ni a los criterios de edición generales ni a los criterios de puntuación en concreto. Así, las elaboradas por Kenneth Adams (1993) y Germán Orduna (1987) del Libro rimado de Palacio, la editada por Fradejas Lebrero del Libro de los engaños o Sendebar (1981) o la edición del Cid de Bayo e Ian (2008) adolecen de la falta de un apartado en el que se detallen los criterios seguidos. Otros autores, en cambio, pese a dedicar un espacio significativo a este fin, no aluden a las decisiones tomadas respecto a la puntuación. Ejemplos de esto son las ediciones de El conde Lucanor de Sotelo (1980) o los Proverbios morales de DíazMas y Mota $(1998)^{15}$.

\subsection{Se moderniza la puntuación}

En la línea de lo que anotaba Roudil, la opción mayoritaria por la mayor parte de los editores es la modernización del sistema puntuario utilizado en los textos medievales. En muchos casos, sin entrar en matices y sin dedicar al asunto apenas un par de líneas, se asume el sistema actual. Con ello no queremos decir que los editores no se basen en las marcas del manuscrito - pues es muy probable que en muchos casos así lo hagan-, sino que no lo explicitan en sus normas de presentación gráfica. «Se puntúa según los usos modernos» (Uría 1992: 116), «Se regula [...] la puntuación según los criterios actuales en todos los casos» (Borsari 2016: 47) o «puntúo de acuerdo con el uso actual» (Serés 1994: CVI) son ejemplos del proceder más habitual en la edición de los textos medievales literarios.

${ }^{14}$ Para facilitar la consulta, se dedica el apartado $\S 6$ de este trabajo a las ediciones consultadas. Además, se ha subdividido atendiendo a los resultados encontrados.

${ }^{15}$ Otras ediciones que siguen este modelo son las siguientes: Blecua (1971), Brey (2015), Cañas (1998), Corominas (1973), Janer (1864), Frenk (2010), García Calvo (1974), García Gómez (1975), Gayangos (1858), González Cuenca (1996), Gutiérrez Martínez (2009-2010), Marín Sánchez (2017: 98), Menéndez Pidal (1902), Menéndez Pidal (1980), Menéndez Pidal y Riquer (1987), Nelson (1979), Zamora Vicente (1970), Icaza (1981), Piriz-Carbonell (1995). 
En unas pocas ocasiones se ha observado que algunos editores justifican esta postura y mencionan el propósito fundamental: facilitar la lectura al lector, pues muchas veces las ediciones no se plantean para un público con una preparación filológica específica, sino para un receptor más amplio. Por ello, es relativamente habitual encontrar aclaraciones como las siguientes: «Para facilitar la lectura, hemos seguido criterios actuales», en la edición de El libro de Apolonio de Corbera (1992: 55), o «esta es una edición dirigida a un público más amplio que el de la filología profesional», en la Poesía de Jorge Manrique (Beltrán 1993: 41) ${ }^{16}$.

\subsection{Se moderniza la puntuación teniendo en cuenta la del manuscrito}

A pesar de que es una recomendación recurrente en los manuales de crítica textual, muy pocos editores manifiestan que hayan tomado en consideración los signos que se encuentran en los manuscritos. Como se ha visto, hay ocasiones en las que los manuscritos utilizados no están puntuados o su uso es arbitrario y con un valor que difiere del actual; sin embargo, hay autores que declaran basarse $-\mathrm{o}$ al menos tomar como referencia- los signos propios del texto, aun siendo conscientes de la dificultad que lleva acomodar los usos de los signos actuales a la prosa o el metro medieval. Precisamente, esta dificultad es la que les lleva en ocasiones a alejarse de las normas dictadas por las Academias y a priorizar la redacción y las estructuras antiguas. En este sentido, por ejemplo, Dutton/González Cuenca (1993: XXXVI) se muestran especialmente críticos con la adopción de las normas modernas de puntuación: «A veces no nos ha sido posible una total fidelidad [a las normas académicas], por la necesidad de acomodarnos a la redacción y sintaxis antiguas, de difícil acomodación a la ortografía moderna». En esta misma línea se sitúa Rubio Tovar (2005-2006: LXXI y LXXII), quien, a pesar de optar en su edición de Viajes medievales por facilitar la tarea al lector, considera que seguir los usos actuales de estos signos «supondría cargar el texto con una constelación de puntos, comas, puntos y comas, etc., completamente ajenas a la prosodia antigua», así como Sanz Julián (2012: C), editor de la Crónica troyana «teniendo en cuenta la peculiar prosa medieval y procurando evitar ambigüedades».

Además de cuidar la prosodia y ritmo medievales, Beltrán Llavador (1997: 192) trataba «de conciliar estos con algunas pautas marcadas por

${ }^{16}$ Otras ediciones que siguen este modelo son las siguientes: Alda Tesán (2001: 70), Cacho Blecua (1987: 208), Casas Rigall (2007: 125), Cejador y Frauca (1963: XXXIX), Chiarini (1964: LXXIII), Ciceri y Rodríguez Puértolas (1990: 39), Criado de Val y Trotter (1984: XIII), Damiani (1974: 33), García Turza (1984: 22), Gómez Moreno y Jiménez Calvente (1994: XLIII), González Muela (1982: 46), Joset (1990: 46), Kany (1925: 276), Kerkhof (1997: 85), Lacarra (1989: 54), Marín Sánchez (2017: 98), Mazzei (1923: 1923), Montaner (2007: 11), Nigris y Serés (1994: LXXXVIII), Rodríguez Puértolas (1996: 53), Rohland y Beltrán (1997: XCVI), Russell (1991: 177), Severin (2012: 47) y Smith (2015: 138). 
los manuscritos» o Fogelquist (2001: 89), en su edición de la Crónica sarracina, afirmaba basarse en «las indicaciones de puntuación que aparecen en el original» ${ }^{17}$.

2.4. Se moderniza la puntuación, se alude a los signos manuscritos y/o se realiza un estudio más o menos detallado

Unas pocas ediciones consultadas modernizan la puntuación y, además, añaden una breve alusión y/o descripción de los signos del manuscrito. Normalmente, en la mayor parte de los casos, esta referencia sirve para apuntar únicamente la inexistencia de estas marcas en el manuscrito. La edición de Montaner del Poema de Mío Cid (1993: 91), la de Wagner del Caballero Zifar (1929: XIII) o la de Gybbon-Monypenny del Libro de buen amor (1988) son claros ejemplos de ello.

En las ediciones cuyos manuscritos utilizados sí presentan puntuación, encontramos dos posturas encontradas: por una parte, los signos de puntuación se consideran poco o nada sistemáticos, como indican Macpherson y Tate en su Libro de los estados (1991: 60); y, por otra, los signos se corresponden con unidades sintácticas o estructurales, por lo que sirven de guía a los estudiosos. En este sentido, García Solalinde, en su edición de la Primera parte de la General estoria (1930: XLVI), afirmaba que el manuscrito, aunque no siempre, le sirvió de gran ayuda «pues a menudo indica acertadamente por medio de punto o de .' la división de las frases, y por calderones la separación de párrafos». De la misma manera, Döhla (2009: 104) añadía que el punto intermedio (·) empleado en los dos manuscritos que coteja de El libro de Calila e Dimna «se corresponde exactamente con nuestra estructuración $»^{18}$.

Son muy pocos los autores que dedican un apartado relativamente extenso a comentar, catalogar o describir los usos con que el copista (o los copistas) utilizaba(n) estos signos. Del corpus de ediciones estudiadas, únicamente hemos encontrado una dedicada a la obra de Diego de San Pedro, Cárcel de Amor, de Corfis (1987: 77 y ss.), en la que se destinan dos páginas aproximadamente a describir y ejemplificar el uso de los signos en los textos que toma para su edición, comparando sus usos del punto (.), de los calderones (\$) o de la barra (/) en los diferentes testimonios del texto. Así, por ejemplo, mientras el uso de los signos en el texto A parece responder a criterios de tipo prosódico y respiratorio, las copias posteriores a 1492 del mismo texto adoptan criterios más sintácticos que rítmicos.

${ }^{17}$ Otras ediciones que siguen este modelo son las siguientes: Haro Cortés (2007: 57), Lucía Megías (2001: xxv) y Morrás (1996).

${ }^{18}$ Otras ediciones que siguen este modelo son las siguientes: Morreale (1996: 168) y Cátedra (1990: 81). 


\subsection{Se conserva la puntuación del manuscrito}

Esta es una de las opciones menos preferidas. Solo hemos encontrado dos casos que siguen este modelo. Antonio Prieto (1976: 61), editor de Siervo libre de amor, afirma que «[s]e ha respetado la puntuación, que no ofrece serias dudas, salvo algún caso que induce a confusión». La única modernización gráfica que aplica es la acentuación gráfica. Por su parte, Michel García (2019), en su edición del Libro del Palacio, estima que introducir signos de puntuación más propios de la prosa podría resultar molesto al aplicarlo al metro del texto en verso. Por ello, toma como referencia los pocos signos que se encuentran en el manuscrito y «[1]a puntuación moderna interviene únicamente cuando la sintaxis no se adecúa a esas pausas, lo que puede provocar confusiones o ambigüedades interpretativas» (García 2019: 106).

\subsection{Se elabora una doble o triple edición}

En tres ocasiones hemos observado que el editor opta por la elaboración de una doble (o triple) edición paleográfica, crítica y, en ocasiones, facsímil. Dos de ellas, la Vida de Santa María Egipciaca (1972) y el Libro de Apolonio (1976) pertenecen a Manuel Alvar, quien afirma en su primera obra que decide «1) presentar una transcripción paleográfica con todo el rigor exigible. 2) Dar una edición crítica [...] para desentrañar los problemas de transmisión que nuestro texto presenta» (Alvar 1972: vol. II, 5). No cabe duda de que este tipo de edición supone un esfuerzo y una dedicación complementarios, además de un coste editorial añadido, pero de esta manera el editor proporciona un texto al que los investigadores de muy diversas disciplinas, ya sean historiadores de la lengua o críticos literarios, pueden recurrir. Exactamente lo mismo realiza Alvar con su Apolonio. En sus criterios de transcripción del segundo tomo, de nuevo detalla las pautas que ha seguido para las dos ediciones. La transcripción paleográfica se realiza siguiendo el original y en la crítica anota que «en nada se perjudica al original utilizando la ortografía actual en todos aquellos casos en que no se perturba el espíritu del autor, o del copista» para facilitar la lectura a un número más amplio de lectores (Alvar 1976: vol. II, 13).

Un caso que nos ha llamado especialmente la atención es la edición del Libro de buen amor de Jean Ducamin de principios del siglo Xx. De la misma forma que hacía Alvar, el hispanista francés cree necesaria una doble edición: «Nous avons cru que l'oeuvre de l'Archiprêtre était assez importante pour mériter une édition paléographique et une édition critique» (Ducamin 1901: XLIV). Sin embargo, a diferencia de las comentadas anteriormente, en las que se establecen dos textos independientes, en este caso parece que se entremezclan ambos tipos de ediciones bajo 
un único texto: se toma como base el manuscrito conocido por la sigla $\mathrm{S}$, del que se hace una transcripción paleográfica, y a pie de página se anotan las variantes en otros manuscritos. Reproduzco a continuación un breve ejemplo de cuatro coplas, que pertenecen a la conocidísima pelea entre don Carnal y doña Cuaresma. Tras ellas se añaden las notas con las variantes del manuscrito G:

1068 Eftando ala mefa con do (sic) jueueo lardero, truxo Amj dos carta $\sigma$ vn lygero trotero ; deoir vos he la $\sigma$ notaf, fer vos tardjnero, ca lao cartao leydaf dy las al menffajero.

1069 De mj, fanta quarefma, fyerua del fraluador, enbiada de djos a todo pecador a todos loo açipreftes E clerigoo con amor, falud en jhe Ju xrifto fafta la pafqua mayor.

1070 fabed que me dixieron que ha çerca de vn año que anda don carnal fañudo, muy eftraño, aftragando mj tierra, faojendo mucho dapño, vertyendo $\overline{m u c h a}$ Ifangre, delo que mal me afano.

1071 E por aquefta Raøón, en vertud obediencia, voo mando firme mente fopena de fetençia que por mj $e$ por mj ayuno $e$ por mj penitençia que lo def afiedes luengo con mj carta de creençia.

G 1068 . - 1. e. en $\overline{m j}$ casa c. j. 1. - 2. traxo, ou : troxo -3 .... laf Nueva $\sigma$ f. v. a tardjnero -4 . La $\sigma$ c... $=1069 .-1$. criador $-3 . .$. cl. fyn $\overline{a m o r}-4$.... . . en p. m. $=1070 .-1$. бepade $\sigma$ q. me dex... - 3. a. la mj t. e $\int$. muy grant daño -4 . enбaño $=1071 .-1$... v. de o. -2 .

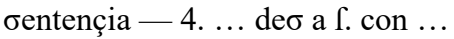

Algunos rasgos propios de una edición paleográfica que se observan en este fragmento son estos: el editor conserva varias grafías para un único fonema (para /s/ encontramos los alógrafos [s], [ [], [ $\sigma]$ y [ []]), mantiene consonantes geminadas al comienzo y en interior de palabra (flaluador, menffajero, กlangre, menffajero), no actualiza el uso de mayúsculas, sino que se siguen las del manuscrito (por aquefta Raбón), las abreviaturas se resuelven utilizando la cursiva (quarefma, clerigoo, pafqua). Sin embargo, a pie de página se recogen las variantes de $\mathrm{G}$ y, en otras coplas, las variantes de T y F. Esta mixtura hace que se trate de una edición particular, con una información sumamente valiosa para el estudioso de cualquier disciplina o rama filológica.

\subsection{Se basa en otras ediciones ya elaboradas}


También se han encontrado ediciones que toman como referencia otras ya realizadas. Es el caso, por ejemplo, del Poema de Fernán González de Alarcos (1955), que se basa en la de Menéndez Pidal; la del Cavallero Zifar de Cristina González (1983), que toma de modelo la de Wagner (1929); la de Guarner (1972), a partir de la elaborada por Boourland; o la del Corbacho de Joaquín González Muela (2003), que se basa en otra de 1955 de Mario Penna publicada en Turín.

En otras ocasiones, hemos visto que algunos editores, además de basarse en ediciones recientes, consultan impresos del siglo XVI. Este es el caso de la edición de El laberinto de Fortuna de José Manuel Blecua (1968: CIII), quien, basándose en la edición realizada por FoulchéDelbosc (1904), la coteja con las de Hernán Núñez y Brocense, ambas del siglo XvI. En la misma línea se encuentra la edición de Keith Whinnom (1973), quien toma de referencia la edición de las obras de Diego de San Pedro elaborada por Gili Gaya y a la vez se fija también en otras traducciones francesas e italianas seiscentistas. La adopción de esta postura por parte de los editores, lamentablemente, no deja ver claramente cuáles son los criterios que subyacen a sus obras, pues se entremezclan las soluciones dadas por los primeros editores y las consultadas.

\subsection{Otras opciones}

Por último, hemos reservado un pequeño apartado para aquellas ediciones que no se ajustan estrictamente a las posturas que se han comentado. Es el caso de la edición del Cancionero de Estúñiga de Salvador Miguel (1977), quien, en un apartado relativamente extenso dedicado a la puntuación del manuscrito, se referencian continuamente las soluciones adoptadas por Manuel y Elena Alvar en su edición. También hemos incluido en este apartado otras ediciones cuyo apartado dedicado a los criterios es, a nuestro parecer, demasiado escaso y no encaja adecuadamente con las tendencias más habituales.

\section{CONSIDERACiOnes Finales}

La edición de los signos de puntuación constituye una de las etapas más complejas en la edición de los textos medievales, ya que «presupone todos los demás pasos» (Sánchez-Prieto 1998: 181), es decir, la comprensión del texto y su transmisión a los lectores.

Los manuales de crítica textual aconsejan, con mayor o menor precisión, la manera en la que el editor debe obrar con respecto a los signos de puntuación, como son la observación de los signos manuscritos o la adecuación al periodo frástico o rítmico medieval, teniendo en 
consideración el tipo de texto que se edita y, lógicamente, sus propias singularidades.

Sin embargo, se constatan grandes diferencias entre el proceder sugerido por los teóricos y la práctica llevada a cabo por los editores. Somos conscientes de que la extensión del apartado habitualmente llamado «Nuestra edición», en el que se indican las decisiones que se han tomado respecto a la dispositio textus, es muy variable y la ausencia de una referencia explícita al asunto que hemos tratado aquí no implica en absoluto que no haya habido un examen previo ni una valoración de los signos manuscritos. No obstante, a partir de las anotaciones que los editores han ofrecido, podemos afirmar que son pocos los que se han detenido en los problemas que plantea la edición de los signos de puntuación, así como en su adaptación al actual sistema. Prueba de ello es el alto porcentaje de ediciones que, sin explicación alguna o con pocos matices (más del $50 \%$ ), modernizan los signos de puntuación para facilitar al lector el entendimiento del texto. El empleo automático de las normas ortográficas dictadas por la Ortografía académica no satisface el objetivo principal de la crítica textual, ya que la aplicación de los criterios sintácticos actuales de la RAE y ASALE (2010) no se adapta adecuadamente a los sistemas empleados en los manuscritos. Aunque su conocimiento es aún muy escaso, como ya se ha mencionado, las investigaciones sobre puntuación medieval indican la diferencia entre la puntuación de los textos en prosa y en verso; pues, mientras los primeros atienden a criterios vinculados con los periodos sintácticos oracionales, los segundos responden a una puntuación rítmica.

Una revisión minuciosa de los signos de puntuación es una laborque merece el mismo trato que el resto de las cuestiones gráficas en el proceso de edición. El estudio cuidadoso de dichas marcas, y su reflejo en las ediciones, contribuye de manera evidente a la interpretación del texto, al conocimiento de la lengua del autor/copista, así como a su usus scribendi (aproximándonos a los criterios que le guían en su proceso de redacción) y a la historia de la puntuación. Por tanto, aunque los estudios minuciosos sobre los rasgos gráficos de una obra, en general, y los de puntuación, en particular, no son objetivos prioritarios de la edición, sí forman parte fundamental de su proceso $y$, en este sentido, consideramos que cuanto mayor sea el conocimiento de los signos interpuntivos -ya sea de una obra en concreto o del periodo medieval- mejores decisiones se podrán tomar, a sabiendas de las particularidades de cada texto. 


\section{REFERENCIAS BIBLIOGRÁFICAS}

BÉDMAR SANCRISTÓBAL, María Elena (2006), «Problemas de edición de textos manuscritos modernos: la puntuación», en Lola Pons Rodríguez (ed.), Historia de la Lengua y Crítica Textual. Madrid/Frankfurt: Iberoamericana/Vervuert, pp. 127-180.

BlecuA, Alberto (1990 [1983]), Manual de crítica textual. Madrid: Castalia.

BlecuA, Alberto (ed.) (2010), Juan Ruiz, Libro de buen amor. Madrid: Cátedra.

BragANTINI-MAILlard, Nathalie (2013), «Réflexions sur la ponctuation éditoriale des textes français médiévaux», Zeitschrift für romanische Philologie, 129/2, pp. 324-365.

FernáNDEZ LóPEZ, María del Carmen (2014), «Estudio contrastivo de hábitos de interpunción en manuscritos medievales castellanos: ¿sistematización en los usos de los copistas?», en María del Rocío Díaz Moreno y Belén Almeida Cabrejas (coords.), Estudios sobre la historia de los usos gráficos en español. Lugo: Axac, pp. 23-72.

GonzÁlez Ollé, Fernando (1980), Lengua y literatura españolas medievales. Textos y glosario. Barcelona: Ariel.

JAUralde Pou, Pablo (1981), Manual de investigación literaria. Guía bibliográfica para el estudio de la literatura española. Madrid: Gredos.

Las Heras Calvo, Miguel (2020), La puntuación sintáctica en la General estoria de Alfonso X el Sabio. [Tesis doctoral]. Universidad de La Rioja.

Llamas Pombo, Elena (2008), «Ponctuer, éditer, lire. État des études sur la ponctuation dans le livre manuscrit», Syntagma: Revista del Instituto de Historia del Libro y de la Lectura, 2, pp. 131-173.

López EstradA, Francisco (1982), «Coloquio en París sobre frases, textos y puntuación en los manuscritos medievales españoles», Dicenda. Cuadernos de Filología Hispánica, 1, pp. 227-231.

Morreale, Margherita (ed.) (1958), Enrique de Villena, Los doze trabajos de Hércules. Madrid: Real Academia Española.

Morreale, Margherita (1980), «Problemas que plantea la interpunción de textos medievales, ejemplificados en un romanceamiento bíblico del siglo XIII», en Josep Roca-Pons (ed.), Homenaje a Agapito Rey. Bloomington: Dept. of Spanish and Portuguese, pp. 151-175.

Orduna, Germán (2005), Fundamentos de crítica textual. Madrid: Arco/ Libros.

PÉREZ PrIEgo, Miguel Ángel (2011), La edición de textos. Madrid: Síntesis. RAE y ASALE (2010), Ortografía de la lengua española. Madrid: Espasa. RouDIL, Jean (1978), «Edition de texte, analyse textuelle et ponctuation (brèves réflexions sur les écrits en prose)», Cahiers de linguistique hispanique médiévale, 3, pp. 269-299. 
Sánchez-Prieto Borja, Pedro (1998), Cómo editar los textos medievales. Criterios para su presentación gráfica. Madrid: Arco/Libros

Sánchez-Prieto Borja, Pedro (2011), La edición de textos españoles medievales y clásicos. Criterios de presentación gráfica. Logroño: Cilengua.

SÁnchez-Prieto Borja, Pedro (2018), «La puntuación en los códices de la General Estoria de Alfonso X el Sabio», Atalaya, 17. En línea: $<\mathrm{http}$ ://journals.openedition.org/atalaya/2570> [consulta: 18/03/2021].

ValcárCel Martínez, Vitalino (ed.) (1982), La Vita Dominici Siliensis de Grimaldo. Logroño: Instituto de Estudios Riojanos.

\section{EDICIONES CONSULTADAS}

\section{a) Ninguna alusión}

Adams, Kenneth (ed.) (1993), Pero López de Ayala, Libro rimado de Palacio. Madrid: Cátedra.

Bayo, Juan Carlos y Ian Michael (eds.) (2008), Cantar de Mio Cid. Madrid: Castalia.

Blecua, José Manuel (ed.) (1971), Don Juan Manuel, El Conde Lucanor o Libro de los enxiemplos del Conde Lucanor et de Patronio. Madrid: Castalia.

Brey, María (ed.) (2015), Juan Ruiz, Libro de buen amor. Madrid: Castalia.

Cañas Murillo, Jesús (ed.) (1998), Libro de Alexandre. Madrid: Cátedra.

Corominas, Joan (ed.) (1973), Juan Ruiz, Libro de buen amor. Madrid: Gredos.

Díaz-Mas, Paloma y Carlos Mota (eds.) (1998), Sem Tob de Carrión, Proverbios morales. Cátedra: Madrid.

Fradejas Lebrero, José (ed.) (1981), Sendebar. Libro de los engaños de las mujeres. Madrid: Editora Nacional.

Frenk, Margit (ed.) (2010), Lírica española de tipo popular. Madrid: Cátedra.

García Calvo, Agustín (ed.) (1974), Sem Tob de Carrión, Glosas de Sabiduría o Proverbios Morales y otras rimas. Madrid: Alianza Ed.

GARCÍA GómEZ, Emilio (ed.) (1975), Las jarchas romances de la serie árabe en su marco. Barcelona: Seix Barral.

GaYANGos, Pascual de (ed.) (1858), Alfonso X el Sabio, La gran conquista de ultramar. Madrid: M. Rivadeneyra.

González Cuenca, Joaquín (1996), Diego Hurtado de Mendoza, Cancionero musical de palacio. Madrid: Visor.

GutiérRez MartíneZ, María del Mar (2009-2010), «Edición del Libro de los exemplos por A.B.C. (1 ${ }^{\mathrm{a}}$ parte)», Memorabilia. Boletín de literatura sapiencial, 13, pp. I-VII. 
ICAZA, Francisco de, y José Amador De los Ríos (eds.) (1981), La danza de la Muerte. Madrid: El Árbol.

JANER, Florencio (ed.) (1864), Rodrigo Yáñez, Poema de Alfonso XI, en Poetas castellanos anteriores al siglo XV. Madrid: Rivadeneyra, pp. 477-551.

Menéndez Pidal, Ramón (ed.) (1902), Poema de Yuçuf. Materiales para su estudio. Madrid: Universidad of Michigan Libraries.

MenÉNDEZ PidAL, Ramón (ed.) (1980), Reliquias de la épica. Madrid: Gredos.

Menéndez Pidal, Ramón, Alfonso Reyes y Martín de RiQuer (eds.) (1987), Cantar de Mio Cid. Madrid: Espasa Calpe.

Nelson, Dana Arthur (ed.) (1979), Libro de Alixandre. Madrid: Gredos.

Orduna, Germán (ed.) (1987), Pero López de Ayala, Rimado de Palacio. Madrid: Castalia.

Piriz-CARBonell, Lorenzo (ed.) (1995), Autos sacramentales, cinco piezas de los siglos $X V-X V I$. Madrid: Centro de Estudios y Actividades Culturales.

ShePARD, Sanford (ed.) (1985), Sem Tob de Carrión, Proverbios morales. Madrid: Castalia.

Sotelo, Alfonso (ed.) (1980), Don Juan Manuel, Libro de los exiemplos del Conde Lucanor e Patronio. Madrid: Cátedra.

Zamora Vicente, Alonso (ed.) (1970), Poema de Fernán González. Madrid: Espasa-Calpe.

\section{B) Se moderniza la puntuación}

Alda Tesán, Jesús Manuel (ed.) (2001), Jorge Manrique, Poesía. Madrid: Cátedra.

BorSARI, Elisa (2016), Nuevo catálogo de traducciones anónimas al castellano. Siglos XIV al XVI, en bibliotecas de España, Italia y Portugal. Barcelona: Calambur.

Beltrán, Vicente (ed.) (1993), Jorge Manrique, Poesía. Madrid: Cátedra.

CACHo Blecua, Juan Manuel (ed.) (1987), Garci Rodríguez de Montalvo, Amadís de Gaula. Madrid: Cátedra.

Casas Rigall, Juan (ed.) (2007), Libro de Alexandre. Madrid: Castalia.

Cejador y Frauca, Julio (ed.) (1963), Juan Ruiz, Libro de buen amor. Madrid: Espasa-Calpe.

ChIARINI, Giorgio (ed.) (1964), Juan Ruiz, Libro de buen amor. Napoli: Riccardo Ricciardi.

Ciceri, Marcella y Julio Rodríguez PuérTolas(eds.) (1990), Antón de Montoro, Cancionero. Salamanca: Biblioteca Española del siglo XV.

Corbella, Dolores (ed.) (1992), Libro de Apolonio. Madrid: Cátedra.

Criado de VAL, Manuel y George Douglas Trotter (eds.) (1984), Fernando de Rojas, Tragicomedia de Calixto y Melibea. Libro también llamado La Celestina. Madrid: CSIC. 
Damiani, Bruno Mario (ed.) (1974), Fernando de Rojas, La Celestina. Madrid: Cátedra.

García Turza, Claudio (ed.) (1984), Gonzalo de Berceo, Los Milagros de Nuestra Señora. Logroño: Servicio de Publicaciones de la Universidad de La Rioja.

Gómez Moreno, Ángel y Teresa JimÉnez Calvente (eds.) (1994), Juan de Mena, Obra completa. Madrid: Fundación José Antonio de Castro.

González Muela, Joaquín (ed.) (1982), Libro del Caballero Zifar. Madrid: Castalia.

Joset, Jacques (ed.) (1990), Juan Ruiz, Libro de buen amor. Madrid: Taurus.

Kany, Charles Emil (ed.) (1925), «Proverbios de Salamón. An unedited Old Spanish Poem», en Homenaje ofrecido a Menéndez Pidal. Miscelánea de estudios lingüisticos, literarios e históricos. Madrid: Hernando, vol. I, pp. 269-285.

Kerkhof, Maxim (ed.) (1997), Juan de Mena, Laberinto de Fortuna. Madrid: Castalia.

LaCARra, María Jesús (ed.) (1989), Sendebar. Madrid: Cátedra.

Marín SÁnchez, Ana María (ed.) (2017), Los castigos de Sancho IV: versión extensa (Ms. BNE 6559). Logroño: Cilengua.

Mazzer, Pilade (ed.) (1923), «Proverbios del rey Salamon», Revue Hispanique, 57, pp. 25-35.

Montaner Frutos, Alberto (ed.) (2007), Cantar de Mio Cid. Edición conmemorativa del VIII centenario del manuscrito de Per Abbad (1207-2007). Barcelona: Carrogio.

Nigris, Carla de y Guillermo Serés (eds.) (1994), Juan de Mena, Laberinto de Fortuna y otros poemas. Barcelona: Crítica.

Rodríguez PuÉrtolas, Julio (ed.) (1996), Poema de Mio Cid. Madrid: Akal.

Rohland, Regula y Vicente Beltrán (eds.), (1997), Marqués de Santillana, Comedieta de Ponza, Sonetos, Serranillas y otras obras. Barcelona: Crítica.

Russell, Peter E. (ed.) (1991), Fernando de Rojas, Comedia o tragicomedia de Calisto y Melibea. Madrid: Castalia.

SERÉs, Guillermo (ed.) (1994), Don Juan Manuel, El conde Lucanor. Barcelona: Crítica.

Severin, Dorothy (ed.) (2012), Fernando de Rojas, La Celestina. Madrid: Cátedra.

Smith, Colin (ed.) (2015 [1976]), Poema de Mio Cid. Madrid: Cátedra.

URÍA, Isabel (coord.) (1992), Gonzalo de Berceo, Obra completa. Madrid: Espasa-Calpe. 
C) Se moderniza la puntuación teniendo en cuenta la del manuscrito Beltrán LlaVador, Rafael (ed.) (1997), Gutierre Díaz de Games, El victorial. Salamanca: Ediciones Universidad Salamanca.

Dutton, Brian y Joaquín González Cuenca (eds.) (1993), Cancionero de Juan Alfonso de Baena. Madrid: Visor.

Fogelquist, James Donald (ed.) (2001), Pedro de Corral, Crónica del rey don Rodrigo, postrimero rey de los godos. Crónica sarracina. Madrid: Castalia.

Haro Cortés, Marta (ed.) (2007), Juan de Capua, Exemplario contra los engaños y peligros del mundo. Valencia: Publicacions de la Universitat de València.

Lucía Megías, José Manuel (2001), Antología de libros de caballerías castellanos. Salamanca: Centro de Estudios Cervantinos.

Morrás, María (ed.) (1996), Alfonso de Cartagena, Libros de Tulio: De senectute, De los ofiçios. Alcalá de Henares: Universidad de Alcalá de Henares.

RuBio Tovar, Joaquín (ed.) (2005-2006), Viajes medievales II: Embajada a Tamorlán, Andanzas e viajes de Pero Tafur, Diarios de Colón. Madrid: Fundación José Antonio de Castro.

SAnZ Julián, María (ed.) (2012), Juan Fernández de Heredia, Crónica troyana. Zaragoza: Larumbe.

D) Se moderniza la puntuación, se alude a los signos manuscritos y/o se realiza un estudio más o menos detallado

Cátedra, Pedro M. (ed.) (1990), Los sermones atribvidos a Pero Marín. Van añadidas algunas noticias sobre la predicación castellana de san Vicente Ferrer. Salamanca: Servicio de Publicaciones de la Universidad de Salamanca.

Corfis, Ivy A. (ed.) (1987), Diego de San Pedros's Cárcel de amor. A critical edition. London: Tamesis Books Limited.

DöHla, Hans-Jörg (ed.) (2009), El libro de Calila e Dimna (1251): nueva edición y estudio de los dos manuscritos castellanos. Zaragoza: Instituto de Estudios Islámicos y del Oriente Próximo.

G. Solalinde, Antonio (ed.) (1930), Alfonso X el Sabio, General estoria. Primera parte. Madrid: Centro de Estudios Históricos.

GybBon-MonyPenny, G. B. (ed.) (1988), Juan Ruiz, Libro de buen amor. Madrid: Castalia.

MacPherson, Ian R. y Robert Brian Tate (eds.) (1991), Don Juan Manuel, El libro de los estados. Madrid: Castalia.

Montaner Frutos, Alberto (ed.) y Francisco Rico (intr.) (1993), Cantar de Mio Cid. Barcelona: Crítica.

Morreale, Margherita (ed.) (1996), «La dança general de la Muerte (II)», Revista de Literatura Medieval, VIII, pp. 117-177. 
WaGner, Charles Philip (ed.) (1929), El libro del cauallero Zifar (El Libro del Cauallero de Dios). Ann Arbor: University of Michigan.

F) Se conserva la puntuación del manuscrito

GarcíA, Michel (ed.) (2019), Pero López de Ayala, Libro del Canciller o Libro del Palacio. Bilbao: Universidad del País Vasco.

Prieto, Antonio (ed.) (1976), Juan Rodríguez del Padrón, Siervo libre de amor. Madrid: Castalia.

H) Se realiza doble o triple edición

Alvar, Manuel (ed.) (1972), Vida de Santa María Egipciaca: estudios, vocabulario, edición de textos. Madrid: CSIC.

Alvar, Manuel (ed.) (1976), Libro de Apolonio: edición, introducción y notas. Barcelona: Planeta.

Ducamin, Jean (ed.) (1901), Juan Ruiz, Libro de buen amor. Texte du XIV siècle publié pour la première fois avec les leçons des trois manuscrits connus. Toulouse: Privat.

H) Se basa en otras ediciones ya elaboradas

Alarcos Llorach, Emilio (ed.) (1955), Poema de Fernán González. Madrid: Castalia.

Blecua, José Manuel (ed.) (1968), Juan de Mena, El laberinto de fortuna o Las Trescientas. Madrid: Escasa-Calpe.

GonzÁlez Muela, Joaquín (ed.) (2003), Alfonso Martínez de Toledo, Arcipreste de Talavera o Corbacho. Madrid: Castalia.

Guarner, Luis (ed.) (1972), Cantar de Rodrigo. San Antonio de Calonge: Ediciones Aubí.

GonzÁlez, Cristina (ed.) (1983), Libro del Cavallero Zifar. Madrid: Cátedra.

Whinnom, Keith (ed.) (1973), Diego de San Pedro, Obras completas I. Tractado de amores. De arnalte y Lucenda. Sermón. Madrid: Castalia.

I) Otras opciones

CáTEDRA, Pedro M. (ed.) (1984-1994), Marqués de Villena, Los doce trabajos de Hércules. Cantabria: Universidad de Cantabria.

Ruiz Casanova, José Francisco (ed.) (1999), Diego de San Pedro, Cárcel de amor. Arnalte y Lucenda. Sermón. Madrid: Cátedra.

Salvador Miguel, Nicasio (ed.) (1977), La poesía cancioneril: el Cancionero de Estúniga. Madrid: Alhambra. 


\title{
$\cos$
}

\section{EN TORNO A LOS CRITERIOS Y CONSIDERACIONES SOBRE LA PUNTUACIÓN EN EDICIONES CRÍTICAS DE TEXTOS LITERARIOS MEDIEVALES}

RESUMEN: La fijación de los signos de puntuación constituye uno de los aspectos más complejos en la elaboración de las ediciones críticas medievales, ya que el editor se ve obligado a tomar diversas elecciones interpretativas sobre un aspecto, los signos interpuntivos, cuyo conocimiento se encuentra aún en sus albores. Por ello, este trabajo pretende, por una parte, revisar cuáles son las orientaciones que algunos de los manuales teóricos de crítica textual más notables aconsejan para el establecimiento de los signos de puntuación en la edición de obras literarias medievales y, por otra, examinar y clasificar los criterios que se adoptaron para la elaboración de 85 ediciones de textos literarios de este periodo. En otras palabras, se pretende cotejar si hay una correspondencia entre las recomendaciones (y criterios) de los primeros y las consideraciones que los editores realizan sobre esta cuestión en su correspondiente apartado.

Palabras Clave: Puntuación. Grafemática. Literatura medieval. Criterios de edición. Crítica textual.

\section{ON CRITERIA AND CONSIDERATIONS ABOUT PUNCTUATION IN CRITICAL EDITION OF SPANISH LITERARY TEXTS}

\begin{abstract}
Punctuation marks constitute one of the most complex aspects in the elaboration of medieval critical editions. The editor is forced to make various interpretative choices about medieval punctuation, a vast area of research whose surface has barely been scratched. For this reason, this work aims, on the one hand, to review the guidelines that publications on textual criticism advise for the establishing of punctuation marks in the editions of medieval literary works. On the other hand, it seeks to examine and classify the criteria that 85 editions of literary texts of this period followed for their elaboration. In other words, it aims to establish whether there is a correspondence between the recommendations (and criteria) of the first, and the considerations that editors make about this issue in their corresponding section.
\end{abstract}

Keywords: Punctuation. Graphemics. Medieval literature. Editing criteria. Textual criticism. 